OPEN ACCESS

Edited by:

Xiao Jun Allen Liu, University of Oklahoma, United States

Reviewed by:

Dafeng Hui,

Tennessee State University, United States

Shutao Chen,

Nanjing University of Information Science and Technology, China

*Correspondence:

Zhenhua Zheng

zzh6711@sina.com

Yanxia Zhao

zhyx8698@163.com

Specialty section:

This article was submitted to

Soil Processes,

a section of the journal

Frontiers in Environmental Science

Received: 20 May 2021

Accepted: 12 July 2021

Published: 22 July 2021

Citation:

Shen $H$, Zhang L, Meng $H$, Zheng $Z$, Zhao $Y$ and Zhang $T$ (2021) Response of Soil Respiration and Its Components

to Precipitation Exclusion in Vitex negundo Var. Heterophylla Shrubland of the Middle Taihang Mountain in

North China.

Front. Environ. Sci. 9:712301.

doi: 10.3389/fenvs.2021.712301

\section{Response of Soil Respiration and Its Components to Precipitation Exclusion in Vitex negundo Var. Heterophylla Shrubland of the Middle Taihang Mountain in North China}

\author{
Huitao Shen ${ }^{1,2}$, Lingkai Zhang ${ }^{3}$, Henan Meng ${ }^{1,2}$, Zhenhua Zheng ${ }^{1,2 *}$, Yanxia Zhao ${ }^{1,2 *}$ and \\ Tao Zhang ${ }^{1}$

\begin{abstract}
${ }^{1}$ Institute of Geographical Sciences, Hebei Academy of Sciences, Shiijazhuang, China, ${ }^{2}$ Hebei Engineering Research Center for Geographic Information Application, Institute of Geographical Sciences, Hebei Academy of Sciences, Shijiazhuang, China,

${ }^{3}$ Southwest Forestry University, School of Ecological and Environmental Sciences, Kunming, China
\end{abstract}

Assessing the response of soil heterotrophic and autotrophic respiration to climate change is critical for forecasting terrestrial carbon cycle behavior in the future. In the present study, we conducted a drought experiment in Vitexnegundo var. heterophylla shrub ecosystem of the Middle Taihang Mountain. Three precipitation manipulation treatments (natural conditions/ambient precipitation (CK), reduced precipitation by $30 \%$ (PE30), and reduced precipitation by 60\% (PE60)) were used to study the impact of different levels of precipitation exclusion on total soil respiration $\left(R_{s}\right)$ and its heterotrophic $\left(R_{h}\right)$ and autotrophic $\left(R_{a}\right)$ components. Our results showed that the rates of $R_{s}$ and its components were significantly decreased under the precipitation exclusion treatments. The proportion of $R_{h}$ in $R_{s}$ reduced from $72.6 \%$ for $\mathrm{CK}$ to $71.9 \%$ under PE60. The annual cumulative $C$ fluxes of $R_{s}$ decreased by $47.8 \mathrm{~g} \mathrm{C} \mathrm{m}^{-2}$ in PE30 and $106.0 \mathrm{~g} \mathrm{C} \mathrm{m}^{-2}$ in PE60, respectively. An exponential relationship was observed between the rate of each soil respiration component and soil temperature in all treatments $(p<0.01)$. Moreover, each soil respiration component rate was better represented by a quadratic model which included soil moisture $(p<0.01)$. However, including both of soil temperature and soil moisture did not explain more variation in soil respiration components compared than the regression model with soil moisture only. In addition, excluding precipitation increased the temperature sensitivity ( $Q_{10}$ values) of $R_{s}$ and its $R_{a}$ and $R_{h}$ components compared to the control. Collectively, our findings suggest that increased drought will inhibit the release of carbon from the soil to the atmosphere, and will likely decrease the contribution of $R_{h}$ to $R_{s}$ in this semiarid shrubland ecosystem.

Keywords: climate change, precipitation exclusion, soil respiration, soil moisture, soil temperature 


\section{INTRODUCTION}

In future climate scenarios, the intensity and frequency of precipitation is forecasted to decrease in many areas (IPCC, 2013; Sun et al., 2019). Reductions in precipitation induced by climate change will greatly impact terrestrial carbon (C) cycling, including soil respiration $\left(R_{s}\right)$, especially in arid and semiarid regions (Ahlström et al., 2015; van der Molen et al., 2011). Terrestrial ecosystems release approximately $58 \mathrm{Pg} \mathrm{CO}_{2}$ per year, which is 10 times more than fossil fuels emissions (Schlesinger and Andrews, 2000; Huang et al., 2018). Accordingly, even small changes in $R_{s}$ may influence inter-annual fluctuations in $\mathrm{C}$ cycling, with subsequent feedbacks on climate change (Bond-Lamberty and Thomson, 2010; Liu et al., 2021).

Responses of $R s$ to decreasing precipitation have been studied in various ecosystems, but considerable uncertainty remains about the directions and magnitude of the response (HinkoNajera et al., 2015; Sotta et al., 2007; van Straaten et al., 2010; Wei et al., 2016). Precipitation reduction was reported to suppress $R_{s}$ in arid and semiarid ecosystems (Talmon et al., 2011) but enhance it in tropical rainforests (Cleveland et al., 2010; Zhang et al., 2015). These contradictory results have been attributed to differences in vegetation types, climatic conditions, and soil microbial activities (Li et al., 2020; Liu et al., 2016). $R_{s}$ is comprised of autotrophic respiration $\left(R_{a}\right)$, produced by the activities of vegetation roots and associated organisms, and heterotrophic respiration $\left(R_{h}\right)$, associated with decomposition of soil organic matter (SOM) through soil biota (Luo and Zhou, 2006). These two components represent different biological and ecological processes and respond differently to changes in environmental factors including soil temperature $\left(T_{s}\right)$ and soil moisture $\left(M_{s}\right)$ (Liu et al., 2016). For example, reduced precipitation strongly suppressed $R_{a}$, but had no effect on $R_{h}$ in a temperate broadleaved evergreen eucalypt forest (Hinko-Najera et al., 2015). Therefore, identifying differences between $R_{a}$ and $R_{h}$ and the factors that control them in different precipitation treatments could help to reduce some of uncertainties associated with climate-carbon feedback forecasts (Liu et al., 2016; Huang et al., 2018; Zhang et al., 2015). However, very few studies have combined manipulating precipitation with partitioning $R_{s}$ into its component fluxes in semiarid shrublands.

Shrublands are a widely distributed biome type in China (Piao et al., 2009), covering approximately 1.23 million $\mathrm{km}^{2}$ of China (Yang et al., 2016). The arid and semi-arid shrublands are important land-cover types in northern China, which are affected by increasing temperatures and changing precipitation patterns (Jia et al., 2016). Moreover, the region of arid and semiarid shrublands is projected to be characterized by large fluctuations in precipitation and frequent drought periods under future climate change (Liu et al., 2012). Thus, it is important to better understand the response of soil respiration components to changing precipitation by using an artificial precipitation manipulation experiment. In the present study, we established precipitation shelters in mountain shrublands of northern China to identify: 1) the impacts of precipitation exclusion on the different soil respiration component rates and their temperature sensitivity values, and 2) the relation between soil respiration components and soil temperature/moisture.

\section{MATERIALS AND METHODS}

\section{Study Area and Plot Setting}

This research was carried out at the Hilly Ecosystem Experimental Station of Taihang Mountain, Chinese Academy of Science $\left(114^{\circ} 15^{\prime} 50^{\prime \prime}\right.$ E, $37^{\circ} 52^{\prime} 44^{\prime \prime} \mathrm{N}, 350 \mathrm{~m}$ a.s.l.) in the Hebei Province of northern China. This region has a semi-arid continental climate with an annual mean atmospheric temperature of $13^{\circ} \mathrm{C}$. The lowest average temperature in January is $-4^{\circ} \mathrm{C}$, and the highest average air temperature in July is $26^{\circ} \mathrm{C}$ (Zeng et al., 2014). Annual mean precipitation is about $560 \mathrm{~mm}$ concentrated from June to September (Shen et al., 2014). Monthly accumulated precipitation and average air temperature during the experimental period are shown in Figure 1. The soil is categorized as Cinnamon soil under the Chinese soil taxonomy, which is equal to Ustalf in the USDA Soil Taxonomy (Zeng et al., 2014). The most abundant shrub is Vitex negundo var. heterophylla, which forms a relatively closed canopy (Shen et al., 2014).

The experiment was carried out in June 2015. Based on a randomized block design, three replicate treatments were used to create precipitation gradients, including natural conditions/ ambient precipitation (CK), reduced precipitation by $30 \%$ (PE30), and reduced precipitation by $60 \%$ (PE60). This design resulted in a total of nine plots. Each experimental plot of $10 \mathrm{~m} \times$ $10 \mathrm{~m}$ was established with $10 \mathrm{~m}$ spacing between plots. All measurements were carried out at the center $(8 \mathrm{~m} \times 8 \mathrm{~m})$ to avoid edge effects. In PE30 and PE60 treatments, precipitation was reduced by 30 and $60 \%$, respectively, by using plastic rainout shelters as described by Sherman et al. (2012). Although the shelters minimally intercepted incoming light, past work has shown that the interception has little effect on plant responses (Zhang et al., 2017).

\section{Measurement of Soil Respiration and Its Components}

A mini-trenching method was adopted to measure $R_{h}$ in the subplots. In each plot, three trenches were excavated $(0.5 \mathrm{~m}$ high and $0.4 \mathrm{~m}$ in diameter) and then the roots were removed.

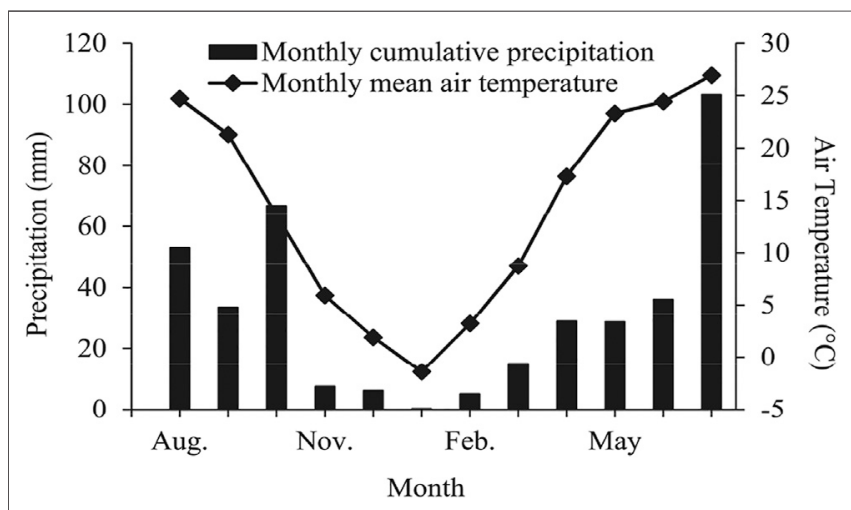

FIGURE 1 | Climatic data during the study period from August 2016 to July 2017. 
Subsequently, the soil was put into nylon mesh bags (mesh size of $0.038 \mathrm{~mm}$ ) to avoid roots expanding into the subplots and to allow the movement of soil organic nutrients, microbes, and soil water (Zhang et al., 2014). Finally, the soil was placed back into the trenches. Vegetation was restricted from the area inside each trench by manually cutting plant growth throughout the study period.

In each plot, three PVC collars (inner diameter of $10.4 \mathrm{~cm}$ and height of $8 \mathrm{~cm}$ ) were installed in the soil at $5 \mathrm{~cm}$ depth to monitor $R_{s}$ in the untrenched area. In addition, another three PVC collars were inserted at the center of the trenching areas to measure $R_{h}$. In order to remove the impacts of soil collar installation on $R_{s}$ or $R_{h}$ measurements, the collars were installed one year before measurements were collected (July 2015). Moreover, living vegetation inside the PVC collars was removed before monitoring (Fang et al., 2018). $R_{s}$ and $R_{h}$ were monitored on clear days once every month between August 2016 and July 2017 using a LI-COR 8100 infrared gas analyzer. All measurements of $R_{s}$ and $R_{h}$ were carried out from 8:00 to 11:00 a.m. $R_{a}$ was calculated by subtracting $R_{h}$ from $R_{s}$ (Sun et al., 2019). The soil temperature and humidity sensors equipped with the LI-COR 8100 system were used to record $T_{s}$ and $M_{s}$ at a soil depth of $10 \mathrm{~cm}$ (Shen et al., 2014).

\section{Statistical Analyses}

An exponential model was used to calculate the relationship between monthly mean $R_{s}, R_{a}$, and $R_{h}$ and monthly mean $T_{s}\left({ }^{\circ} \mathrm{C}\right)$ from three replicates (Sun et al., 2019):

$$
R=a \cdot \mathrm{e}^{b \cdot T_{s}} \text { and } Q_{10}=\mathrm{e}^{10 \cdot b}
$$

where $R$ stands for $R_{s}, R_{a}$, or $R_{h}\left(\mu \mathrm{mol} \mathrm{m} \mathrm{m}^{-2} \mathrm{~s}^{-1}\right) ; T_{s}$ is the soil temperature $\left({ }^{\circ} \mathrm{C}\right) ; a$ and $b$ are regression parameters; $Q_{10}$ is the temperature sensitivity of different soil respiration components.

A polynomial function (Sun et al., 2019) was established to analyze the variation between monthly mean $R_{s}, R_{a}$, or $R_{h}$ and monthly mean $M_{s}(\%)$ as follows:

$$
R=c \cdot M_{s}^{2}+d \cdot M_{s}+e
$$

where $R$ stands $R_{s}, R_{a}$, or $R_{h}\left(\mu \mathrm{mol} \mathrm{m} \mathrm{m}^{-2} \mathrm{~s}^{-1}\right) ; c, d$, and $e$ are functional parameters; $M_{s}$ is the soil moisture (\%).

To consider the combined impacts of $T_{s}$ and $M_{s}$ on soil respiration components, we also fitted soil respiration components using a two-factor regression model (Zhang et al., 2015) as follows:

$$
R=f \cdot \mathrm{e}^{g \cdot T_{s}} \cdot M_{s}^{h}
$$

Where $\mathrm{R}$ represents $R_{s}, R_{a}$, or $R_{h}\left(\mu \mathrm{mol} \mathrm{m} \mathrm{s}^{-2}\right) ; f, g$, and $h$ are regression parameters; $T_{s}$ and $M_{s}$ are the soil temperature $\left({ }^{\circ} \mathrm{C}\right)$ and soil moisture (\%) at $10 \mathrm{~cm}$ depth, respectively.

According to the method described by Shen et al. (2014), $R_{s}$ and $R_{h}$ measurements between respective sampling dates were interpolated and summed to estimate the annual cumulative fluxes for different treatments.

Repeated measures ANOVA analysis was used to examine the significant differences in mean $T_{s}, M_{s}, R_{s}, R_{a}, R_{h}$ and $R_{h} / R_{s}$ between the $C K$ and treatment plots for various periods.
ANOVA was also performed to test the effect of precipitation treatment on the mean soil respiration components, environmental factors, and cumulative soil respiration component fluxes. All analyses were performed using SPSS 13.0 software (SPSS for Windows, Chicago, IL). Significant differences were indicated at the level of $p<0.05$. Exponential model 1) and polynomial model 2) and their corresponding coefficients were performed using Sigmplot 12 (Systat Software Inc., CA, United States of America); non-linear regression model 3 ) and its regression parameters were performed using R 4.1.0 for Windows (https://www.r-project.org).

\section{RESULTS}

\section{Soil Temperature and Soil Moisture}

Soil temperature varied seasonally, from the lowest of $-2.8^{\circ} \mathrm{C}$ in January 2017 to the highest of $26.9^{\circ} \mathrm{C}$ in July 2017 (Figure 2A). Mean monthly $T_{s}$ depth for CK, PE30 and PE60 were 14.1, 13.9 and $13.8^{\circ} \mathrm{C}$, respectively, and there was not a significant difference among the three treatments throughout the study period (Figure 2B).

Soil moisture in the three precipitation gradients displayed similar seasonal variation (Figure 2C). On average, $M_{s}$ was $10.2 \%$ in CK and decreased by 5.0 and $17.8 \%$ in PE30 and PE60, respectively (Figure 2D). In addition, soil in PE60 was significantly drier than the soil in the control $(p<0.05)$.

\section{$\boldsymbol{R}_{s}$ and Its Components}

During the study period, $R_{s}, R_{h}$, and $R_{a}$ showed similar seasonal variation to $T_{s}$ and $M_{s}$, with maximum values occurring during summer (July) and minimum values occurring in the winter (Figure $\mathbf{3 A}, \mathbf{C}, \mathbf{E}$ ). However, the ratio of $R h / R_{s}$ showed an opposite pattern with the lowest value (approximately 60\%) during the peak season (Figure 3G). The average $R_{s}$ was $1.48 \pm 0.14 \mu \mathrm{mol} \mathrm{m}^{-2} \mathrm{~s}^{-1}$ in $\mathrm{CK}$, and was reduced by 8.5 and $18.8 \%$ in $\mathrm{PE} 30$ and PE60, respectively; the reduction in $R_{s}$ was significant for PE60 $(p<0.05)$ (Figure 3B). The average $R_{h}$ was $1.07 \pm 0.09,0.98 \pm 0.08$, and $0.88 \pm 0.04 \mu \mathrm{mol} \mathrm{m}{ }^{-2} \mathrm{~s}^{-1}$ in CK, PE30, and PE60, respectively. The mean $R_{a}$ was $0.41 \pm 0.08 \mu \mathrm{mol} \mathrm{m}^{-2} \mathrm{~s}^{-1}$ in CK, with a reduction of $7.5 \%$ in PE30 and $19.9 \%$ in PE60, respectively (Figure 3D,F). The one-way ANOVA showed that the average $R_{h}$ was significantly higher in CK than in PE60 (Figure 3D). In contrast, $R_{a}$ was not significantly altered by changing precipitation (Figure 3F). In addition, precipitation exclusion did not significantly alter the ratio of $R h / R_{s}$ (Figure $3 \mathrm{H}$ ). $R_{h}$ was significantly and positively correlated to $R_{s}$ under the three precipitation manipulation treatments (Figure 4). The model implied that $R_{h}$ approached zero with $R_{s}$, which made sense biologically as $R_{h}$ occurred in the soil when $R_{s}>0$ (Bond-Lamberty et al., 2004). Annually, reducing precipitation significantly decreased the cumulative $R_{s}$ by $47.8 \mathrm{~g} \mathrm{C} \mathrm{m}^{-2}$ in $\mathrm{PE} 30$ and $106.0 \mathrm{~g} \mathrm{C} \mathrm{m}^{-2}$ in PE60, respectively (Figure 5). Moreover, the contribution of $R_{h}$ to $R_{s}$ was altered by different precipitation treatments, with a larger $R_{h} / R_{s}$ ratio in $\mathrm{CK}$ than in PE30 and PE60. 


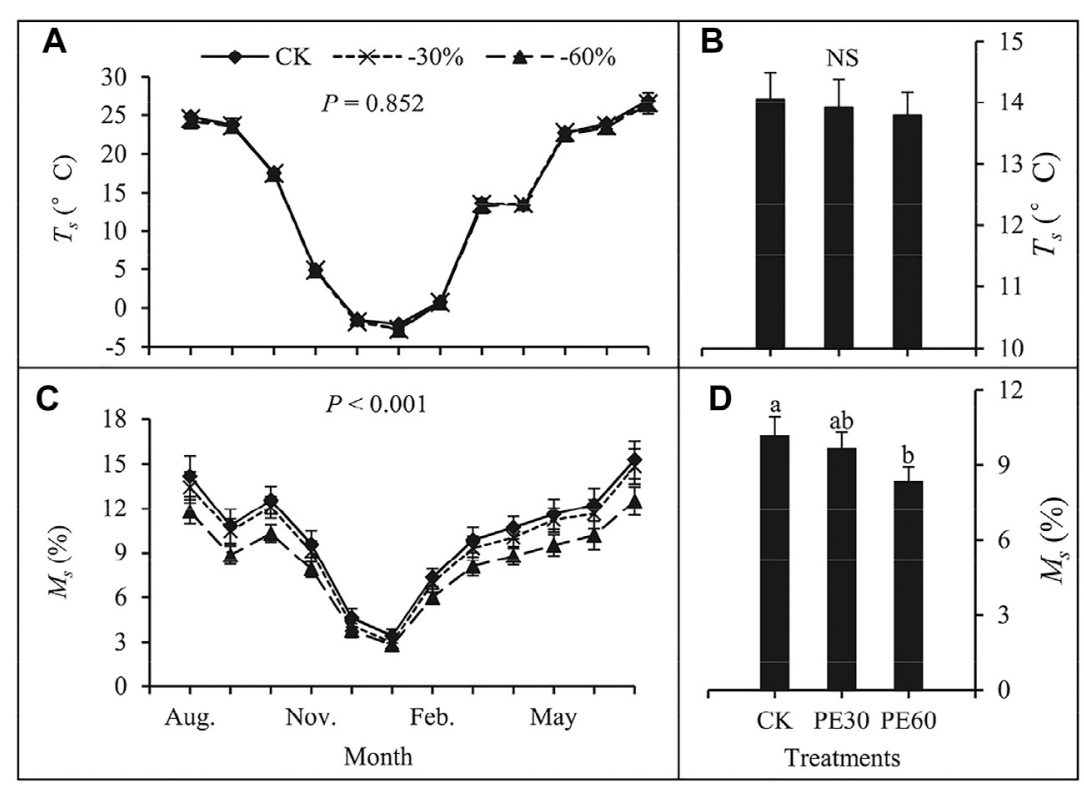

FIGURE 2 | Seasonal variation in (A) soil temperature $\left(T_{S}\right)$ at $10 \mathrm{~cm}$ depth, and $(\mathbf{C})$ soil moisture $\left(M_{s}\right)$ at $10 \mathrm{~cm}$ depth from August 2016 to July 2017 . Data are the mean $\pm \mathrm{SD}(n=3)$. Monthly mean values of (B) $T_{s}$ and (D) $M_{s}$ throughout the study period. Letters on the top of the bars indicate significant difference among treatments at level of $p<0.05$. CK: ambient precipitation; PE30: 30\% reduced precipitation; PE60: $60 \%$ reduced precipitation.

\section{Effects of Soil Temperature and Moisture on Soil Respiration Components}

Both $R_{s}$ and its $R_{h}$ and $R_{a}$ components increased exponentially with $T_{s}(p<0.01)$ for the three precipitation treatments (Table 1$)$. $T_{s}$ interpreted $68.2-78.9 \%$ of the variations in $R_{s}, R_{h}$, and $R_{a}$ (Table 1). The $Q_{10}$ values of $R_{s}, R_{h}$, and $R_{a}$ varied from 3.35 to $4.57,2.12$ to 2.20 , and 3.60 to 4.35 , respectively. Moreover, the $Q_{10}$ of $R_{s}$ and $R_{a}$ both significantly increased with reduced precipitation, while the $Q_{10}$ of $R_{h}$ did not. A significant quadratic relationship was observed between soil respiration components and $M_{s}(p<0.01)$ measured at $10 \mathrm{~cm}$ depth (Table 2). $M_{s}$ explained $76.1-78.6 \%$ of the variation in $R_{s}$, $71.8-74.5 \%$ in $R_{h}$, and $76.9-81.6 \%$ in $R_{a}$, respectively (Table 2); thus, $M_{s}$ was a better predictor of soil respiration components in the three precipitation treatments. Moreover, simultaneously considering both $T_{s}$ and $M_{s}$ explained $56.6-77.9 \%$ of the variation in soil respiration components ( $p<0.01$ or $p<0.05$ ) (Table 3), indicating that the inclusion of $T_{s}$ did not improve the explanation of soil respiration components compared to the model based on $M_{s}$ only.

\section{DISCUSSION}

\section{Segmentation of Soil Respiration}

The average $R_{s}$ in this study ranged from $1.20 \pm 0.09 \mu \mathrm{mol} \mathrm{m}^{-2} \mathrm{~s}^{-1}$ to $1.48 \pm 0.14 \mu \mathrm{mol} \mathrm{m} \mathrm{m}^{-2} \mathrm{~s}^{-1}$, which was in the range of values reported for other shrubland ecosystems (de Dato et al., 2010; Shi et al., 2020; Talmon et al., 2011). The relative contribution of $R_{h}$ to $R_{s}$ was $72.6,72.3$ and $71.9 \%$ in CK, PE30 and PE60, respectively.
These were consistent with the values reported by Cheng et al. (2015) and Huang et al. (2018), but were higher than those reported in other ecosystems (Comstedt et al., 2011; Huang et al., 2016; Saiz et al., 2005). The trenching method has been widely utilized to distinguish $R_{h}$ from $R_{s}$ in many ecosystems (Hanson et al., 2000; Kukumägi et al., 2017; Liu et al., 2016). Nevertheless, it should be noted that a long period of time (i.e., more than 6 months) might be needed to completely remove the influence of dead roots on $R_{h}$ (Xu et al., 2015; Lei et al., 2017). In order to eliminate the impacts of dead root decomposition on $R_{h}$ measurements, we inserted collars into the trenches almost one year before the measurement of soil respiration components. However, the trenching method may lead to low estimates of $R_{h}$ due to removal of inputs from root exudates and dead roots (Yi et al., 2007; Fang et al., 2018).

\section{Effects of Precipitation Manipulation on $\boldsymbol{R}_{s}$ and Its Components}

Precipitation can affect $R_{s}$ and its components by changing soil humidity, which directly influences the substrates for heterotrophic respiration as well as the autotrophic respiration of roots and microorganisms (Wang et al., 2014b; Liu et al., 2018; Sun et al., 2019). Consistent with several previous works (Balogh et al., 2016; Borken et al., 2006; Suseela et al., 2012), a decrease in $R_{s}$ and its $R_{h}$ and $R_{a}$ components was also observed under the precipitation exclusion treatments in the present study, and this response can be explained by a number of abiotic and biotic mechanisms. First, reductions in $R_{h}$, and hence $R_{s}$, were possibly caused by lower soil moisture due to decreased precipitation (Yang et al., 2020). Reduced precipitation might inhibit $R_{h}$ and $R_{s}$ 


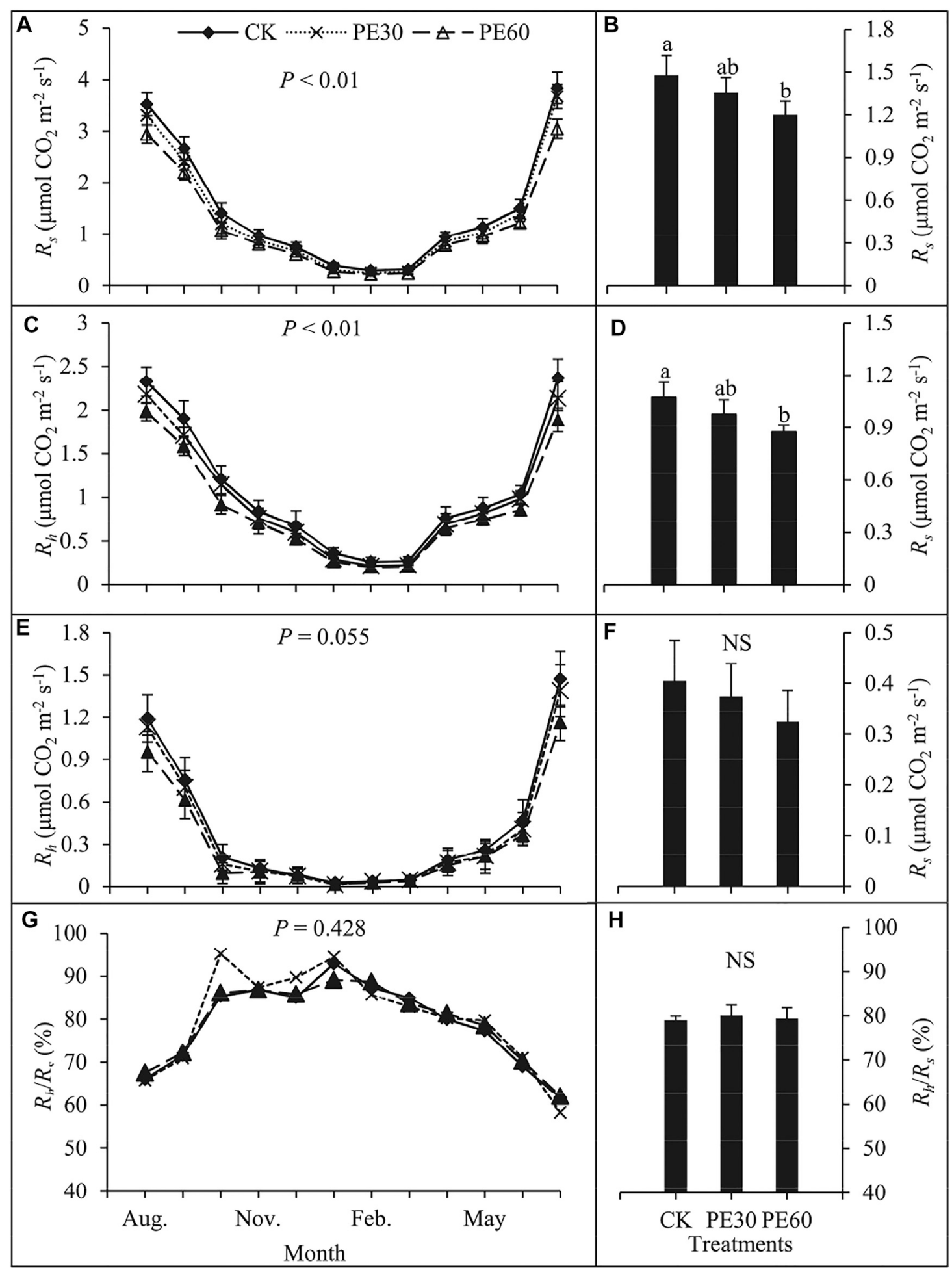

FIGURE 3| Seasonal variations in (A) total soil respiration $\left(R_{s}\right)$ and its $(\mathbf{C})$ heterotrophic $\left(R_{h}\right)$ and $(\mathbf{E})$ autotrophic $\left(R_{a}\right)$ components and $(\mathbf{G})$ the ratio of $R_{h} / R_{s}(\%)$ from August 2016 to July 2017. Data are the mean $\pm \mathrm{SD}(n=3)$. Monthly mean values of $(\mathbf{B}) R_{S},(\mathbf{D}) R_{h},(\mathbf{F}) R_{a}$ and $(\mathbf{H})$ ratio of $R_{h} / R_{S}(\%)$ throughout the study period. Letters on the top of the bars indicate significant difference among treatments at level of $p<0.05$. CK: ambient precipitation; PE30: 30\% reduced precipitation; PE60: $60 \%$ reduced precipitation. 


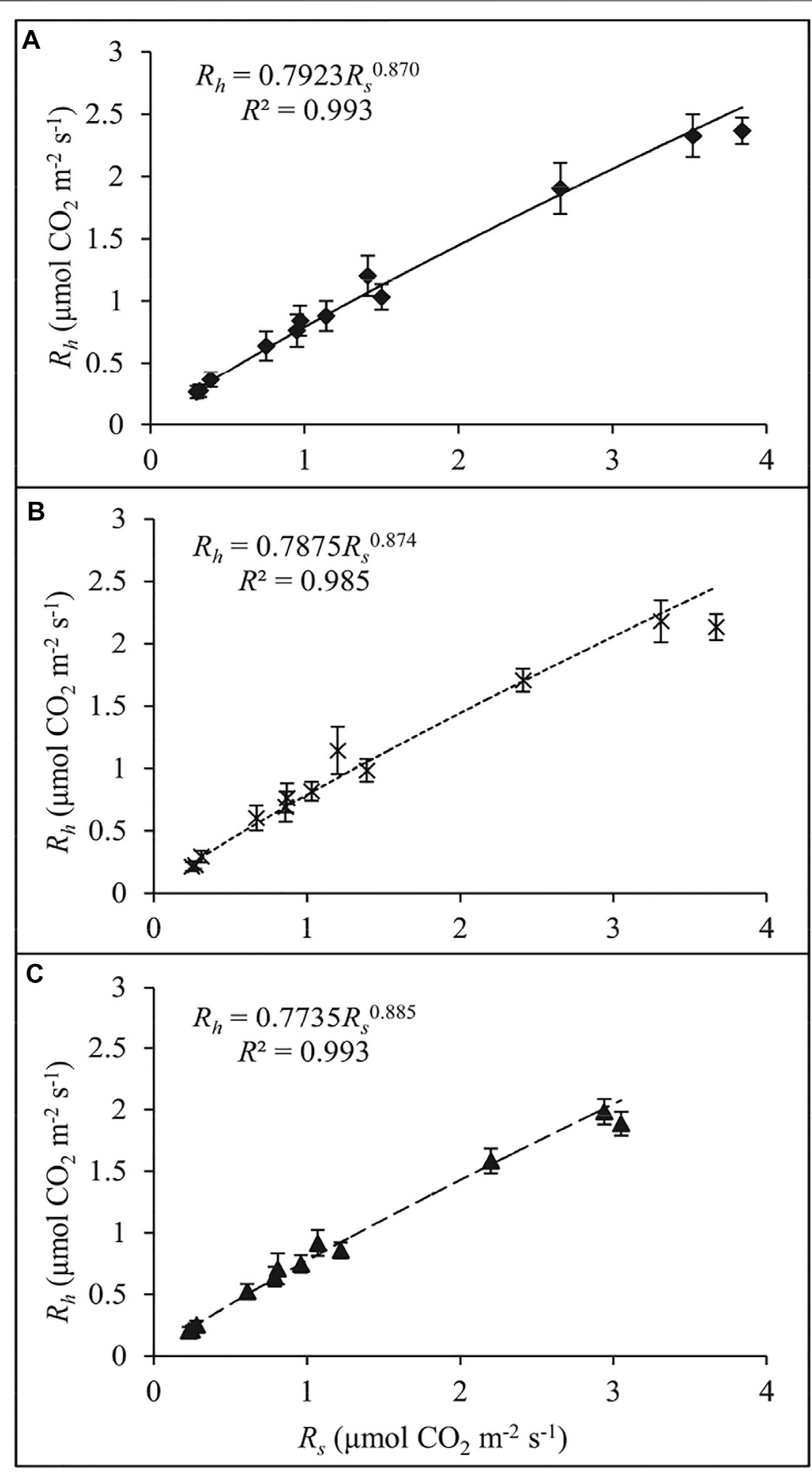

FIGURE 4 | Relationship between soil respiration $\left(R_{S}\right)$ and its heterotrophic $\left(R_{h}\right)$ component during the study period. (A) CK: ambient precipitation; (B) PE30: 30\% reduced precipitation; (C) PE60: 60\% reduced precipitation.

by impeding the diffusion of unstable substrates, and thus decreasing the rates of soluble substrates absorption by microorganisms (Yan et al., 2011). Second, lower fine root growth caused by lower soil moisture levels might also explain the effect of decreased precipitation on $R_{s}$ and its components (Hinko-Najera et al., 2015). Third, lower soil moisture in 


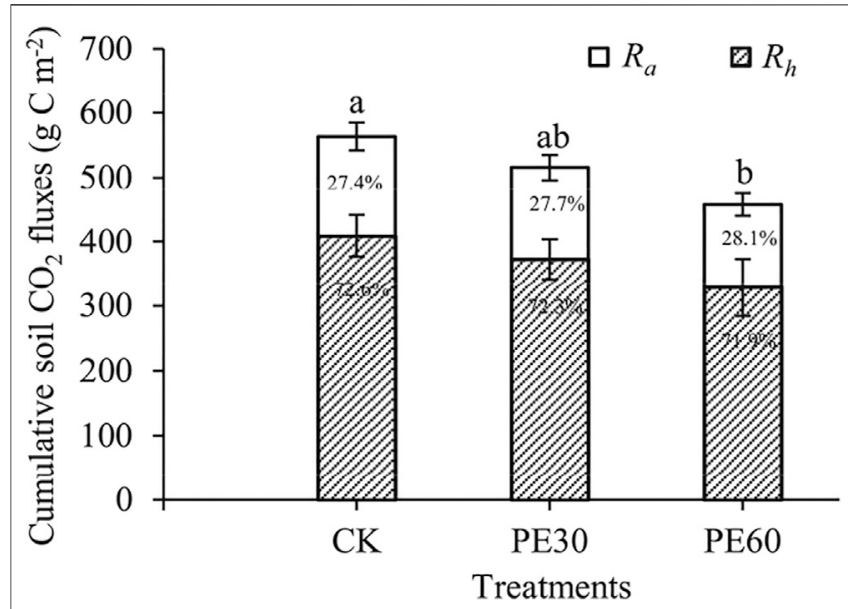

FIGURE 5 | The ratio of heterotrophic respiration $\left(R_{h}\right)$ and autotrophic respiration $\left(R_{a}\right)$ to cumulative soil respiration components fluxes $\left(\mathrm{g} \mathrm{C} \mathrm{m}^{-2}\right)$ from August 2016 to July 2017. Letters on the top of the bars indicate significant difference among treatments at level of $p<0.05$. CK: ambient precipitation; PE30: 30\% reduced precipitation; PE60: $60 \%$ reduced precipitation.

TABLE 1 | Impacts of soil temperature $\left(T_{S},{ }^{\circ} \mathrm{C}\right)$ on the variation of different soil respiration components $\left(R, \mu \mathrm{mol} \mathrm{m} \mathrm{m}^{-2} \mathrm{~s}^{-1}\right) . R^{2}, p$, and $Q_{10}$ values are reported.

\begin{tabular}{|c|c|c|c|c|}
\hline Treatment & Equation & $R^{2}$ & $p$ & $Q_{10}$ \\
\hline \multicolumn{5}{|l|}{ Soil respiration $\left(R_{S}\right)$} \\
\hline Ambient precipitation (CK) & $R_{s}=0.135 \mathrm{e}^{0.121 T s}$ & 0.753 & $<0.01$ & 3.35 \\
\hline $\begin{array}{l}30 \% \text { reduced precipitation } \\
\text { (PE30) }\end{array}$ & $R_{s}=0.067 \mathrm{e}^{0.148 T s}$ & 0.763 & $<0.01$ & 4.39 \\
\hline $\begin{array}{l}60 \% \text { reduced precipitation } \\
\text { (PE60) }\end{array}$ & $R_{s}=0.108 \mathrm{e}^{0.152 T s}$ & 0.749 & $<0.01$ & 4.57 \\
\hline \multicolumn{5}{|l|}{ Heterotrophic respiration $\left(R_{h}\right)$} \\
\hline Ambient precipitation (CK) & $R_{s}=0.281 \mathrm{e}^{0.075 T s}$ & 0.682 & $<0.01$ & 2.12 \\
\hline $\begin{array}{l}30 \% \text { reduced precipitation } \\
\text { (PE30) }\end{array}$ & $R_{s}=0.244 \mathrm{e}^{0.077 T_{s}}$ & 0.690 & $<0.01$ & 2.16 \\
\hline $\begin{array}{l}60 \% \text { reduced precipitation } \\
\text { (PE60) }\end{array}$ & $R_{s}=0.216 \mathrm{e}^{0.079 T s}$ & 0.689 & $<0.01$ & 2.20 \\
\hline \multicolumn{5}{|l|}{ Autotrophic respiration $\left(R_{a}\right)$} \\
\hline Ambient precipitation (CK) & $R_{s}=0.0003 \mathrm{e}^{0.128 T s}$ & 0.789 & $<0.01$ & 3.60 \\
\hline $\begin{array}{l}30 \% \text { reduced precipitation } \\
\text { (PE30) }\end{array}$ & $R_{S}=0.0006 \mathrm{e}^{0.133 T s}$ & 0.783 & $<0.01$ & 3.78 \\
\hline $\begin{array}{l}60 \% \text { reduced precipitation } \\
\text { (PE60) }\end{array}$ & $R_{s}=0.0008 \mathrm{e}^{0.147 T s}$ & 0.761 & $<0.01$ & 4.35 \\
\hline
\end{tabular}

decreased precipitation treatments might increase the amount of $\mathrm{CO}_{2}$ that accumulates in soil pores (Liu et al., 2019).

However, many other studies have reported varying responses of soil respiration to reduced precipitation (Deng et al., 2018; Zhang et al., 2015). Davidson et al. (2008) found no effect of reduced precipitation on soil respiration, indicating that belowground carbon allocation may not have been significantly impacted by reduced precipitation. In addition, Cleveland et al. (2010) and Zhang et al. (2015) reported that reducing precipitation increased soil respiration in tropical rainforest experiments because the soils responded to the increase of dissolved organic matter concentrations or soil $\mathrm{O}_{2}$ availability. The reasons for these inconsistent results may be due to the fact that they were conducted in diverse ecosystems and measurements were conducted on different temporal scales (Wang et al., 2014b). Therefore, it is necessary to quantitatively assess the changes of $R_{s}$ and its components under different intensities and frequencies of precipitation exclusion in different ecosystems.

\section{Effects of Precipitation Manipulation on Modeled Soil Respiration Components}

Soil temperature exhibited seasonal variation, which primarily accounted for the temporal variation of soil respiration components (Fang et al., 2018). In this study, both $R_{s}$ and its components rose exponentially with the increase of $T_{s}$ in the three precipitation treatments, consistent with previous findings from shrublands (Lellei-Kovács et al., 2016; Sun et al., 2021) and other ecosystems (Rey et al., 2002; Zhang et al., 2015). Mechanisms underlying the response of soil respiration components to changes in $T_{s}$ may include the availability of nutrients and substrates, the adaptation of roots to different soil environments, and the alteration of the microbial community (Wei et al., 2016). In addition to $T_{s}, M_{s}$ has also been considered an important variable that controls the variation of $R_{s}$ and its components (Saiz et al., 2005; Sun et al., 2019). Our results provided evidence that the precipitation manipulation treatments significantly decreased $M_{s}$ and had a much stronger effect on both $R_{s}$ and its components. $M_{s}$ might limit soil respiration components by stressing the distribution of assimilates in the plant-soil system, microorganisms, and enzymatic activities in the rhizosphere (Escolar et al., 2015; Sanaullah et al., 2011). According to the $M_{s}$-based quadratic function, both $R_{s}$ and its components may become depressed when $M_{s}$ becomes either too high or too low (Liu et al., 2018). We simulated the soil respiration components with a two-factor model (Eq. 3) (Table 3) which turned out to be weaker than the $M_{s}$-based model, suggesting that precipitation exclusion amplified the effects of soil water limitation on soil respiration (Sun et al., 2019).

$Q_{10}$ is recognized as an important parameter to evaluate temperature adaptation of $R_{s}$ (Luo and Zhou, 2006; Fang et al., 2018). In our work, the values of $Q_{10}$ ranged from 2.12 to 4.57 , which was consistent with the range (0.65-5.18) of other ecosystems (Rey et al., 2002; Zou et al., 2018; Sun et al., 2021). Previous studies have suggested that drought might change the sensitivity of $R_{s}$ to temperature and disrupt the coupling between temperature and humidity (Selsted et al., 2012; Wang et al., 2014b). Soil-water deficit adequately weakened the sensitivity of $R_{s}$ to $T_{s}$, leading to the decrease of $Q_{10}$ (Rey et al., 2002; Wang et al., 2014b; Liu et al., 2016). In contrast, our study found that reducing precipitation increased the $Q_{10}$ values of different soil respiration components, which was consistent with previous results in a grassland ecosystem (Sun et al., 2019). The $Q_{10}$ values of $R_{a}$ were higher than those of $R_{h}$, reflecting a tighter relationship between $Q_{10}$ and plant root activities (Sun et al., 2019; Zou et al., 2018). In addition, the results also suggested that $R_{h}$ was less sensitive than $R_{a}$ to the precipitation exclusion treatments, indicating that drought might have a weaker 
TABLE 2 | Impacts of soil moisture $\left(M_{s}, \%\right)$ on the variation of different soil respiration components $\left(R, \mu \mathrm{mol} \mathrm{m}^{-2} \mathrm{~s}^{-1}\right) . R^{2}$ and $p$ values are reported.

\begin{tabular}{|c|c|c|c|}
\hline Treatment & Equation & $R^{2}$ & $p$ \\
\hline \multicolumn{4}{|l|}{ Soil respiration $\left(R_{S}\right)$} \\
\hline Ambient precipitation (CK) & $R_{s}=0.044 M_{s}^{2}-0.548 M_{s}+2.014$ & 0.778 & $<0.01$ \\
\hline $30 \%$ reduced precipitation (PE30) & $R_{s}=0.042 M_{s}^{2}-0.498 M_{s}+1.664$ & 0.786 & $<0.01$ \\
\hline $60 \%$ reduced precipitation (PE60) & $R_{s}=0.051 M_{s}^{2}-0.518 M_{s}+1.561$ & 0.761 & $<0.01$ \\
\hline \multicolumn{4}{|l|}{ Heterotrophic respiration $\left(R_{h}\right)$} \\
\hline Ambient precipitation (CK) & $R_{s}=0.024 M_{s}^{2}-0.291 M_{s}+1.234$ & 0.733 & $<0.01$ \\
\hline $30 \%$ reduced precipitation (PE30) & $R_{s}=0.022 M_{s}^{2}-0.236 M_{s}+0.933$ & 0.745 & $<0.01$ \\
\hline $60 \%$ reduced precipitation (PE60) & $R_{s}=0.028 M_{s}^{2}-0.269 M_{s}+0.929$ & 0.718 & $<0.01$ \\
\hline \multicolumn{4}{|l|}{ Autotrophic respiration $\left(R_{a}\right)$} \\
\hline Ambient precipitation (CK) & $R_{s}=0.019 M_{s}^{2}-0.257 M_{s}+0.779$ & 0.816 & $<0.01$ \\
\hline $30 \%$ reduced precipitation (PE30) & $R_{s}=0.018 M_{s}^{2}-0.229 M_{s}+0.631$ & 0.790 & $<0.01$ \\
\hline $60 \%$ reduced precipitation (PE60) & $R_{s}=0.023 M_{s}^{2}-0.250 M_{s}+0.641$ & 0.769 & $<0.01$ \\
\hline
\end{tabular}

TABLE 3 | Combined impacts of soil temperature $\left(T_{s},{ }^{\circ} \mathrm{C}\right)$ and soil moisture $\left(M_{s}, \%\right)$ on the variation of different soil respiration components $\left(R, \mu \mathrm{mol} \mathrm{m} \mathrm{m}^{-2} \mathrm{~s}^{-1}\right) \cdot R^{2}$ and $p$ values are reported.

\begin{tabular}{|c|c|c|c|}
\hline Treatment & Equation & $R^{2}$ & $p$ \\
\hline \multicolumn{4}{|l|}{ Soil respiration $\left(R_{S}\right)$} \\
\hline Ambient precipitation (CK) & $R_{S}=0.560 e^{0.068 T s} M_{s}^{-0.136}$ & 0.628 & $<0.05$ \\
\hline $\begin{array}{l}30 \% \text { reduced precipitation } \\
\text { (PE30) }\end{array}$ & $R_{S}=0.487 \mathrm{e}^{0.056 T s} M_{s}^{-0.105}$ & 0.566 & $<0.05$ \\
\hline $\begin{array}{l}60 \% \text { reduced precipitation } \\
\text { (PE60) }\end{array}$ & $R_{s}=0.035 e^{0.105 T s} M_{s}^{0.106}$ & 0.779 & $<0.01$ \\
\hline \multicolumn{4}{|l|}{ Heterotrophic respiration $\left(R_{h}\right)$} \\
\hline Ambient precipitation (CK) & $R_{s}=0.487 e^{0.072 T s} M_{s}^{-0.152}$ & 0.627 & $<0.05$ \\
\hline $\begin{array}{l}30 \% \text { reduced precipitation } \\
\text { (PE30) }\end{array}$ & $R_{s}=0.419 \mathrm{e}^{0.059 T s} M_{s}^{-0.112}$ & 0.568 & $<0.05$ \\
\hline $\begin{array}{l}60 \% \text { reduced precipitation } \\
\text { (PE60) }\end{array}$ & $R_{s}=0.016 e^{0.096 T s} M_{s}^{0.447}$ & 0.775 & $<0.01$ \\
\hline \multicolumn{4}{|l|}{ Autotrophic respiration $\left(R_{a}\right)$} \\
\hline Ambient precipitation (CK) & $R_{s}=0.427 e^{0.071 T s} M_{s}^{-0.136}$ & 0.635 & $<0.05$ \\
\hline $\begin{array}{l}30 \% \text { reduced precipitation } \\
\text { (PE30) }\end{array}$ & $R_{s}=0.363 e^{0.059 T s} M_{s}^{-0.092}$ & 0.585 & $<0.05$ \\
\hline $\begin{array}{l}60 \% \text { reduced precipitation } \\
\text { (PE60) }\end{array}$ & $R_{s}=0.039 \mathrm{e}^{0.112 T s} M_{s}^{-0.106}$ & 0.728 & $<0.01$ \\
\hline
\end{tabular}

feedback mechanism of SOM decomposition on climate change (Sun et al., 2018).

\section{CONCLUSION}

The present study provided unique data for exploring the impacts of precipitation exclusion on $R_{s}$ and its components in a semiarid mountain shrubland of northern China. Precipitation exclusion significantly depressed $R_{s}$ and its $R_{h}$ and $R_{a}$ components. $R_{s}$ and its components were all exponentially related with $T_{s}$ and quadratically related with $M_{s}$. The temperature sensitivity $\left(Q_{10}\right)$ of $R_{s}$ and $R_{a}$ were both significantly increased by decreased precipitation. In addition, decreasing the intensity of precipitation decreased the contribution of $R_{h}$ to $R_{s}$. We estimated an annual $\mathrm{C}$ reduction release of 47.8 and $106.0 \mathrm{~g} \mathrm{C} \mathrm{m}^{-2}$ in response to treatments that decreased precipitation by 30 and $60 \%$, respectively. Our findings are critical for understanding and forecasting possible changes in the release of carbon by semiarid shrublands in response to climate change. Further work with long-term experiments is necessary to evaluate the influence of precipitation manipulation treatments on soil respiration components and how the responses may vary along under future drought events.

\section{DATA AVAILABILITY STATEMENT}

The raw data supporting the conclusions of this article will be made available by the authors, without undue reservation.

\section{AUTHOR CONTRIBUTIONS}

HS was involved with experiment plan, data collection and analysis, manuscript formation and manuscript editing. LZ, $\mathrm{HM}$, and TZ collected the data. $\mathrm{ZZ}$ and $\mathrm{YZ}$ edited the manuscript.

\section{FUNDING}

The present study was funded by the Natural Science Foundation of Hebei Province (Grant No. C2019302018), the Natural Science Foundation of China (Grant No. 31500448), the Youth Talent Project of Hebei Province, and the Talent Training Program of Hebei Academy of Sciences (Grant No. 2020G16).

\section{ACKNOWLEDGMENTS}

The authors would like to thank Elizabeth Tokarz at Yale University for her assistance with polishing up the manuscript. 


\section{REFERENCES}

Ahlström, A., Raupach, M. R., Schurgers, G., Smith, B., Arneth, A., Jung, M., et al. (2015). The Dominant Role of Semi-arid Ecosystems in the Trend and Variability of the Land $\mathrm{CO}_{2}$ Sink. Science 348 (6237), 895-899. doi:10.1126/ science.aaa1668

Balogh, J., Papp, M., Pintér, K., Fóti, S., Posta, K., Eugster, W., et al. (2016). Autotrophic Component of Soil Respiration Is Repressed by Drought More Than the Heterotrophic One in Dry Grasslands. Biogeosciences 13, 5171-5182. doi:10.5194/bg-13-5171-2016

Bond-Lamberty, B., and Thomson, A. (2010). Temperature-associated Increases in the Global Soil Respiration Record. Nature 464 (7288), 579-582. doi:10.1038/ nature 08930

Bond-Lamberty, B., Wang, C. K., and Gower, S. T. (2004). A Global Relationship between the Heterotrophic and Autotrophic Components of Soil Respiration?. Glob. Chang. Biol. 10, 1756-1766. doi:10.1111/ j.1365-2486.2004.00816.x

Borken, W., Savage, K., Davidson, E. A., and Trumbore, S. E. (2006). Effects of Experimental Drought on Soil Respiration and Radiocarbon Efflux from a Temperate forest Soil. Glob. Chang. Biol. 12, 177-193. doi:10.1111/j.13652486.2005.001058.x

Cheng, X. Q., Kang, F. F., Han, H. R., Liu, H. W., and Zhang, Y. L. (2015). Effect of Thinning on Partitioned Soil Respiration in a Young Pinus Tabulaeformis Plantation during Growing Season. Agric. For. Meteorol. 214-215, 473-482. doi:10.1016/j.agrformet.2015.09.016

Cleveland, C. C., Wieder, W. R., Reed, S. C., and Townsend, A. R. (2010). Experimental Drought in a Tropical Rain forest Increases Soil Carbon Dioxide Losses to the Atmosphere. Ecology 91, 2313-2323. doi:10.1890/091582.1

Comstedt, D., Boström, B., and Ekblad, A. (2011). Autotrophic and Heterotrophic Soil Respiration in a Norway spruce forest: Estimating the Root Decomposition and Soil Moisture Effects in a Trenching experiment. Biogeochemistry 104, 121-132. doi:10.1007/s10533-010-9491-9

Davidson, E. A., Nepstad, D. C., Ishida, F. Y., and Brando, P. M. (2008). Effects of an Experimental Drought and Recovery on Soil Emissions of Carbon Dioxide, Methane, Nitrous Oxide, and Nitric Oxide in a Moist Tropical forest. Glob. Chang. Biol. 14, 2582-2590. doi:10.1111/j.1365-2486.2008.01694.x

de Dato, G. D., De Angelis, P., Sirca, C., and Beier, C. (2010). Impact of Drought and Increasing Temperatures on Soil $\mathrm{CO}_{2}$ Emissions in a Mediterranean Shrubland (Gariga). Plant Soil 327, 153-166. doi:10.1007/s11104-009-0041-y

Deng, Q., Zhang, D. Q., Han, X., Chu, G. W., Zhang, Q. F., and Hui, D. F. (2018). Changing Rainfall Frequency rather Than Drought Rapidly Alters Annual Soil Respiration in a Tropical forest. Soil Biol. Biochem. 121, 8-15. doi:10.1016/ j.soilbio.2018.02.023

Escolar, C., Maestre, F. T., and Rey, A. (2015). Biocrusts Modulate Warming and Rainfall Exclusion Effects on Soil Respiration in a Semi-arid Grassland. Soil Biol. Biochem. 80, 9-17. doi:10.1016/j.soilbio.2014.09.019

Fang, C., Li, F. M., Pei, J. Y., Ren, J., Gong, Y. H., Yuan, Z. Q., et al. (2018). Impacts of Warming and Nitrogen Addition on Soil Autotrophic and Heterotrophic Respiration in a Semi-arid Environment. Agric. For. Meteorol. 248, 449-457. doi:10.1016/j.agrformet.2017.10.032

Hanson, P. J., Edwards, N. T., Garten, C. T., and Andrews, J. A. (2000). Separating Root and Soil Microbial Contributions to Soil Respiration: a Review of Methods and Observations. Biogeochemistry 48 (1), 115-146. doi:10.1023/A: 1006244819642

Hinko-Najera, N., Fest, B., Liversley, S. J., and Arndt, S. K. (2015). Reduced Throughfall Decreases Autotrophic Respiration, but Not Heterotrophic Respiration in a Dry Temperate Broadleaved evergreen forest. Agric. For. Meteorol. 200, 66-77. doi:10.1016/j.agrformet.2014.09.013

Huang, W. J., Han, T. F., Liu, J. X., Wang, G. S., and Zhou, G. Y. (2016). Changes in Soil Respiration Components and Their Specific Respiration along Three Successional Forests in the Subtropics. Funct. Ecol. 30 (8), 1466-1474. doi:10.1111/1365-2435.12624

Huang, S. D., Ye, G. F., Lin, J., Chen, K. T., Xu, X., Ruan, H. H., et al. (2018). Autotrophic and Heterotrophic Soil Respiration Responds Asymmetrically to Drought in a Subtropical forest in the Southeast China. Soil Biol. Biochem. 123, 242-249. doi:10.1016/j.soilbio.2018.04.029
IPCC (2013). The Physical Science Basis. Contribution of Working Group I to the Fifth Assessment Report of the Intergovernmental Panel on Climate Change. Cambridge: Cambridge University Press.

Jia, X., Zha, T. S., Gong, J. N., Wu, B., Zhang, Y. Q., Qin, S. G., et al. (2016). Energy Partitioning over a Shrubland in Northern China. Hydrol. Process. 30 (6), 972-985. doi:10.1002/hyp.10685

Kukumägi, M., Ostonen, I., Uri, V., Helmisaari, H., Kanal, A., Kull, O., et al. (2017). Variation of Soil Respiration and its Components in Hemiboreal Norway spruce Stands of Different Ages. Plant Soil 414, 265-280. doi:10.1007/s11104016-3133-5

Lei, L., Xiao, W. F., Zeng, L. X., Zhu, J. H., Huang, Z. L., Cheng, R. M., et al. (2017). Thinning but Not Understory Removal Increased Heterotrophic Respiration and Total Soil Respiration in Pinus Massoniana Stands. Sci. Total Environ. 621, 1360-1369. doi:10.1016/j.scitotenv.2017.10.092

Lellei-Kovács, E., Botta-Dukát, Z., de Dato, G., Estiarte, M., Guidolotti, G., Kopittke, G. R., et al. (2016). Temperature Dependence of Soil Respiration Modulated by Thresholds in Soil Water Availability across European Shrubland Ecosystems. Ecosystems 19, 1460-1477. doi:10.1007/s10021-016-0016-9

Li, Y., Zhou, Z. X., Lei, L. J., Ru, J. Y., Song, J., Zhou, M. X., et al. (2020). Asymmetric Responses of Soil Respiration in Three Temperate Steppes along a Precipitation Gradient in Northern China Revealed by Soil-Monolith Transplanting experiment. Agric. For. Meteorol. 294, 108126. doi:10.1016/ j.agrformet.2020.108126

Liu, R., Pan, L. P., Jenerette, G. D., Wang, Q. X., Cieraad, E., and Li, Y. (2012). High Efficiency in Water Use and Carbon Gain in a Wet Year for a Desert Halophyte Community. Agric. For. Meteorol. 162-163, 127-135. doi:10.1016/ j.agrformet.2012.04.015

Liu, Y. C., Liu, S. R., Wan, S. Q., Wang, J. X., Luan, J. W., and Wang, H. (2016). Differential Responses of Soil Respiration to Soil Warming and Experimental Throughfall Reduction in a Transitional oak forest in central China. Agric. For. Meteorol. 226-227, 186-198. doi:10.1016/j.agrformet.2016.06.003

Liu, Y. T., Li, J., Jin, Y. Q., Zhang, Y. P., Sha, L. Q., Grace, J., et al. (2018). The Influence of Drought Strength on Soil Respiration in a Woody savanna Ecosystem, Southwest China. Plant Soil. 428, 321-333. doi:10.1007/s11104018-3678-6

Liu, Y. C., Zhao, C. C., Shang, Q., Su, L., and Wang, L. (2019). Responses of Soil Respiration to spring Drought and Precipitation Pulse in a Temperate oak forest. Agric. For. Meteorol. 268, 289-298. doi:10.1016/j.agrformet.2019.01.029

Liu, Y. Z., Zhao, C. C., Guo, J. W., Zhang, L. N., Xuan, J., Chen, A. Q., et al. (2021). Short-term Phosphorus Addition Augments the Effects of Nitrogen Addition on Soil Respiration in a Typical Steppe. Sci. Total Environ. 761, 143211. doi:10.1016/j.scitotenv.2020.143211

Luo, Y. Q., and Zhou, X. H. (2006). Soil Respiration and the Environment. New York: Academic Press. doi:10.1016/B978-012088782-8/50012-7

Piao, S. L., Fang, J. Y., Ciais, P., Peylin, P., Huang, Y., Sitch, S., et al. (2009). The Carbon Balance of Terrestrial Ecosystems in China. Nature 458, 1009-1013. doi:10.1038/nature07944

Rey, A., Pegoraro, E., Tedeschi, V., Parri, I. D., Jarvis, P. G., and Valentini, R. (2002). Annual Variation in Soil Respiration and its Components in a Coppice oak forest in Central Italy. Glob. Chang. Biol. 8 (9), 851-866. doi:10.1046/j.13652486.2002.00521.x

Saiz, G., Byrne, K. A., Butterbach-bahl, K., Kiese, R., Blujdea, V., and Farrell, E. P. (2005). Stand Age-Related Effects on Soil Respiration in a First Rotation Sitka Spruce Chronosequence in Central Ireland. Glob. Chang. Biol. 12 (6), 1007-1020. doi:10.1111/j.1365-2486.2006.01145.x

Sanaullah, M., Blagodatskaya, E., Chabbi, A., Rumpel, C., and Kuzyakov, Y. (2011). Drought Effects on Microbial Biomass and Enzyme Activities in the Rhizosphere of Grasses Depend on Plant Community Composition. Appl. Soil Ecol. 48, 38-44. doi:10.1016/j.apsoil.2011.02.004

Schlesinger, W. H., and Andrews, J. A. (2000). Soil Respiration and the Global Carbon Cycle. Biogeochemistry 48, 7-20. doi:10.1023/A:1006247623877

Selsted, M. B., Linden, L., Ibrom, A., Michelsen, A., Larsen, K. S., Pedersen, J. K., et al. (2012). Soil Respiration Is Stimulated by Elevated $\mathrm{CO}_{2}$ and Reduced by Summer Drought: Three Years of Measurements in a Multifactor Ecosystem Manipulation experiment in a Temperate Heathland (CLIMAITE). Glob. Chang. Biol. 18, 1216-1230. doi:10.1111/j.1365-2486.2011.02634.x

Shen, H. T., Cao, J. S., Zhang, W. J., Zeng, X. H., and Wang, H. R. (2014). Winter Soil $\mathrm{CO}_{2}$ Flux from Different Mid-latitude Sites from Middle Taihang 
Mountain in North China. PLoS ONE. 9 (3), e91589. doi:10.1371/ journal.pone.0091589

Sherman, C., Sternberg, M., and Sternberger, Y. (2012). Effect of climate change on soil respiration and carbon processing in Mediterranean and semi-arid regions: An experimental approach. Eur. J. Soil Boil. 52, 48-58. doi:10.1016/ j.ejsobi.2012.06.001

Shi, P., Qin, Y. L., Liu, Q., Zhu, T. T., Li, Z. B., Li, P., et al. (2020). Soil Respiration and Response of Carbon Source Changes to Vegetation Restoration in the Loess Plateau. China. Sci. Total Environ. 707, 135507. doi:10.1016/j.scitotenv.2019.135507

Sotta, E. D., Veldkamp, E., Schwendenmann, L., Guimaraes, B. R., Paixao, R. K., Ruivo, M., et al. (2007). Effects of an Induced Drought on Soil Carbon Dioxide $\left(\mathrm{CO}_{2}\right)$ Efflux and Soil $\mathrm{CO}_{2}$ Production in an Eastern Amazonian Rainforest, Brazil. Glob. Chang. Biol. 13, 2218-2229. doi:10.1111/j.13652486.2007.01416.x

Sun, S. Q., Lei, H. Q., and Chang, S. X. (2019). Drought Differentially Affects Autotrophic and Heterotrophic Soil Respiration Rates and Their Temperature Sensitivity. Biol. Fertil. Soils. 55, 275-283. doi:10.1007/ s00374-019-01347-w

Sun, W. H., Zhao, X. N., Gao, X. D., Shi, W. Y., Ling, Q., Siddique, K. H. M., et al. (2021). Impacts of Land Use Conversion on the Response of Soil Respiration to Precipitation in Drylands: A Case Study with Four-Yearlong Observations. Agric. For. Meteorol. 304-305, 108426. doi:10.1016/ j.agrformet.2021.108426

Suseela, V., Conant, R. T., Wallenstein, M. D., and Dukes, J. S. (2012). Effects of Soil Moisture on the Temperature Sensitivity of Heterotrophic Respiration Vary Seasonally in an Old-Field Climate Change experiment. Glob. Chang. Biol. 18, 336-348. doi:10.1111/j.1365-2486.2011.02516.x

Talmon, Y., Sternberg, M., and Grünzweig, J. M. (2011). Impact of Rainfall Manipulations and Biotic Controls on Soil Respiration in Mediterranean and Desert Ecosystems along an Aridity Gradient. Glob. Chang. Biol. 17 (2), 1108-1118. doi:10.1111/j.1365-2486.2010.02285.x

van der Molen, M. K., Dolman, A. J., Ciais, P., Eglin, T., Gobron, N., Law, B. E., et al. (2011). Drought and Ecosystem Carbon Cycling. Agric. For. Meteorol. 151 (7), 765-773. doi:10.1016/j.agrformet.2011.01.018

van Straaten, O., Veldkamp, E., Kohler, M., and Anas, I. (2010). Spatial and Temporal Effects of Drought on Soil $\mathrm{CO}_{2}$ Efflux in a Cacao Agroforestry System in Sulawesi, Indonesia. Biogeosciences 7, 1223-1235. doi:10.5194/bg-7-12232010

Wang, Y. F., Hao, Y. B., Cui, X. Y., Zhao, H. T., Xu, C. Y., Zhou, X. Q., et al. (2014b). Responses of Soil Respiration and its Components to Drought Stress. J. Soils Sediments 14, 99-109. doi:10.1007/s11368-013-0799-7

Wei, X. R., Zhang, Y. J., Liu, J., Gao, H. L., Fan, J., Jia, X. X., et al. (2016). Response of Soil CO 2 Efflux to Precipitation Manipulation in a Semiarid Grassland. J. Environ. Sci. 45, 207-214. doi:10.1016/j.jes.2016.01.008

Xu, X., Shi, Z., Li, D. J., Zhou, X. H., Sherry, R. A., and Luo, Y. Q. (2015). Plant Community Structure Regulates Responses of Prairie Soil Respiration to
Decadal Experimental Warming. Glob. Chang. Biol. 21, 3846-3853. doi:10.1111/gcb.12940

Yan, L., Chen, S., Huang, J., and Lin, G. (2011). Water Regulated Effects of Photosynthetic Substrate Supply on Soil Respiration in a Semiarid Steppe. Glob. Chang. Biol. 17, 1990-2001. doi:10.1111/j.1365-2486.2010.02365.x

Yang, X., Chi, X. L., Ji, C. J., Liu, H. Y., Ma, W. H., Mohhammat, A., et al. (2016). Variations of Leaf $\mathrm{N}$ and $\mathrm{P}$ Concentrations in Shrubland Biomes across Northern China: Phylogeny, Climate, and Soil. Biogeosciences 13, 4429-4438. doi:10.5194/bg-13-4429-2016

Yang, Z. L., Wei, Y. Y., Fu, G. Y., Song, H. Q., Li, G. Y., and Xiao, R. (2020). Asymmetric Effect of Increased and Decreased Precipitation in Different Periods on Soil and Heterotrophic Respiration in a Semiarid Grassland. Agric. For. Meteorol. 291, 108039. doi:10.1016/j.agrformet.2020.108039

Yi, Z. G., Fu, S. L., Yi, W. M., Zhou, G. Y., Mo, J. M., Zhang, D. Q., et al. (2007). Partitioning Soil Respiration of Subtropical Forests with Different Successional Stages in South China. For. Ecol. Manag. 243 (2-3), 178-186. doi:10.1016/j.foreco.2007.02.022

Zeng, X. H., Zhang, W. J., Shen, H. T., Cao, J. S., and Zhao, X. (2014). Soil Respiration Response in Different Vegetation Types at Mount Taihang, China. Catena 116, 78-85. doi:10.1016/j.catena.2013.12.018

Zhang, C., Niu, D., Hall, S. J., Wen, H., Li, X., Fu, H., et al. (2014). Effects of Simulated Nitrogen Deposition on Soil Respiration Components and Their Temperature Sensitivities in a Semiarid Grassland. Soil Biol. Biochem. 75, 113-123. doi:10.1016/j.soilbio.2014.04.013

Zhang, X., Zhang, Y. P., Sha, L. Q., Wu, C. S., Tan, Z. H., Song, Q. H., et al. (2015). Effects of continuous draught stress on soil respiration in a tropical rainforest in southwest China. Plant Soil 394, 343-353. doi:10.1007/s11104-015-2523-4

Zhang, B., Tan, X. R., Wang, S. S., Chen, M. L., Chen, S. P., Ren, T. T., et al. (2017). Asymmetric Sensitivity of Ecosystem Carbon and Water Processes in Response to Precipitation Change in a Semiarid Steppe. Funct. Ecol. 31 (6), 1301-1311. doi:10.1111/1365-2435.12836

Zou, J. L., Tobin, B., Luo, Y. Q., and Osborne, B. (2018). Response of Soil Respiration and its Components to Experimental Warming and Water Addition in a Temperate Sitka spruce forest Ecosystem. Agric. For. Meteorol. 260-261, 204-215. doi:10.1016/j.agrformet.2018.06.020

Conflict of Interest: The authors declare that the research was conducted in the absence of any commercial or financial relationships that could be construed as a potential conflict of interest.

Copyright (c) 2021 Shen, Zhang, Meng, Zheng, Zhao and Zhang. This is an openaccess article distributed under the terms of the Creative Commons Attribution License (CC BY). The use, distribution or reproduction in other forums is permitted, provided the original author(s) and the copyright owner(s) are credited and that the original publication in this journal is cited, in accordance with accepted academic practice. No use, distribution or reproduction is permitted which does not comply with these terms. 